\title{
Financial and Social Capitals of Elderly People in Thailand
}

\author{
Amornrat Apinunmahakul ${ }^{1}$ \\ ${ }^{1}$ School of Development Economics, National Institute of Development Administration, Bangkok, Thailand \\ Correspondence: Amornrat Apinunmahakul, School of Development Economics, National Institute of \\ Development Administration, 118 SereeThai Road, Bangkrapi, Bangkok 10240, Thailand. Tel: 66-87-327-1447. \\ E-mail: amornrat_a2001@yahoo.com
}

\author{
Received: August 7, 2012 Accepted: August 23, 2012 Online Published: November 30, 2012 \\ doi:10.5539/ass.v8n15p147 URL: http://dx.doi.org/10.5539/ass.v8n15p147
}

\begin{abstract}
The number of ageing population in Thailand has been increased rapidly. The country was ranked as the most aged economy in South-east Asia after Singapore. However, there exists a body of research that associates social connectedness with good health. It hence is the objective of this study to examine of whether the correlation holds for Thai elderly. Using the first round pilot survey on Health, Ageing and Retirement in Thailand (HART), the study found that being married and, the level of education of the respondent contribute positively significantly to the probability of reporting good physical and mental health. The more the elderly participate in social activities, the higher the probability of reporting good or very good health, in particular, the mental health. Social participations to good physical health is an income equivalence of a 5 percent increase in an individual non-labor income, whilst social participations to good mental health accounts to almost 14 percent increase in the total asset value. Participating in voluntary associations thus reduces heath inequalities among older people. The research findings hence advocate for the social involvement of elderly people as a part of the quality ageing policy and the community-based welfare policy.
\end{abstract}

Keyword: ageing, social capital, social connection, elderly health, Thai elderly

\section{Introduction}

Due to longevity of population over the last three decades, the ageing population of Thailand has increased rapidly. The National Economic and Social Development Board of Thailand forecasted that the number of Thai elderly will increase from 8.14 million (12.5 percent of total population) in 2010 to 14.45 million (20 percent of total population) in 2020 .

The United Nations Population Fund (UNFPA, 2006) reported that Thailand was ranked as the second most aged country next to Singapore among the eleven countries in South-East Asia with a fast increase in the elderly dependency ratio (the number of population with 60 years and above divided by the working population.) from $15.5 \%$ in 2005 to $32.2 \%$ in 2025 while the juvenile dependency ratio (the number of population with 18 years and below divided by the working population.) gradually declined from $34.4 \%$ to $28.9 \%$ in the same period. As a result, the population of older persons will surpass that of children for the first time in history of Thailand in 2020.

This rapid change in the demographic structure implies an increase in public spending on social security programs, in particular for the elderly health care and the old age income payment. The rising expenditure on ageing could cut into educational services for younger generation, productive investment in infrastructure, R\&D expenditure, environmental protection, and so forth. Health promotion of the elderly, therefore, becomes a challenge for the sustainable growth of Thai economy.

However, recent research findings has associated social connectedness with good health started from the study by Putnam (2000), Szreter \& Woolcock (2004), Islam, Merlo, Kawachi, Lingstrom, \& Gerthan (2006), Sirven \& Debrand (2008), Ichida, Kondo, Hirai, Hanibuchi, Yoshikawa, \& Murata (2009), and so on. These results correspond to Article 10 of the Political Declaration of the Second World Assembly on Ageing, 2002 in Madrid that "The potential of older persons is a powerful basis for future development. This enables society to rely increasingly on the skills, experiences and wisdom of older persons, not only to take the lead in their own betterment but also to participate actively in that of society as a whole" (United Nation Population Fund (UNFPA) Thailand, 2006) together with the conceptual framework of 'healthy ageing' defined by WHO (2006) 
as a process of increasing opportunities for health to enable older people to take part in society.

It is, therefore, the objective of this study to employ the first wave of the pilot panel survey on Health, Ageing and Retirement in Thailand (HART) to answer two research questions; whether social involvement of Thai elderly help to improve their physical and mental health, and whether social capital or financial capital has more influence on the older adults' health status. Our empirical results show that social participations contribute positively significantly to both physical and mental health of Thai elderly. The contribution of social participations to good physical health is equivalent to a 5 percent increase in an individual non-labor market income, while the contribution of social participations to good mental health is an income equivalence of almost 14 percent increase in the value of an individual total asset.

The paper is structured as follows. Next section discusses about HART survey and presents the descriptive statistics of data used in this study. The econometric framework is presented in section three. Section four analyzes the empirical results. We then conclude in section five.

\section{The Data}

The panel survey on Health, Aging and Retirement in Thailand (HART) was a pilot project funded by National Research Commission of Thailand (NRCT) to a research team at the National Institute of Development Administration (NIDA) aiming to develop a survey instrument similar to those of the longitudinal survey of ageing in other East Asian countries like the Korea Longitudinal Studying of Aging (KLoSA), Chinese Health and Retirement Longitudinal Study (CHARLS), and so forth.

For the first round survey in 2009, NIDA research team undertook a comprehensive survey of 1500 individuals aged 45 years and older residing in Bangkok and the surrounded cities as well as in the northeast province of Khon-Kaen as the precursor to develop and prepare for a full scale panel survey which will take place in 2012.

Similar to KLoSA, HART questionnaire contains an array of information of Thai elderly in seven aspects consisting of personal demography, family support to respondent, individual health status, employment status, labor and non-labor market income, individual asset and liability, and, self- assessment on life satisfaction. A number of questions in KLoSA instrument have been altered to appropriating to the circumstances in Thailand. However, after excluding those who do not answer the questions interested in this study, there are 1461 observations remained for our analysis.

In the section on individual health status, HART questionnaire first asked the respondent to rank his own 'physical health' on the scale from 1 to 5 indicating whether the respondent considered himself of very good, good, fair, bad, or, very bad health respectively. The same question and measuring scale was repeated for the respondent to rate on his 'mental health'. Answers from these two questions were used to construct two binary variables of Self Reported Health $(S R H)$ namely $S R H_{\text {physical }}$, and, $S R H_{\text {mental }}$. The dummy variable $S R H_{\text {physical }}=1$ if the respondent reported that he had good or very good health, and 0 if other health status was reported. The same criteria applied for $S R H_{\text {mental }}$.

'Self-Reported Health', in particular for physical health, is a common measure of an individual's health status in various empirical researches as discussed in Sirven \& Debrand (2008). Idler \& Kasl (1995) found that self-reported physical health was a good predictor of mortality. While numerous researches found a positive correlation of social connectedness with good physical health, the impact of social participation on mental health has rarely been explored. Findings from this research hence will contribute to the study on the effects of an individual's social capital stock on both the physical and mental health in particular that of the Thai elderly.

In general, an individual's level of social capital consists of three major components; an individual social networks with both formal and informal organizations, social trust, and social reciprocity. All forms of social capital will work together in generating social and economic exchange, reduce transaction costs, allow group members of a network to draw on favor, circulate information, and gain better access to opportunities. Social capitals, therefore, provide both private and public returns to those who possess them (Putnam, 2000). However, the study here will focus merely on the contribution of the social participation in formal associations of the elderly to their physical and mental health.

HART survey classified membership to social associations into 7 categories: - (1) Religious organizations, (2) Professional associations, (3) Cultural, art, music, and, sport clubs, (4) Education-related organizations, (5) Voluntary associations, (6) Political parties and non-profit organizations, and, (7) 0ther social associations. From the 1461 observations used in this study, about 18 percent of the samples were members to at least one association.

Being aware that those who joined sport club were more likely healthier than those who did not, Table 1 
summarized the types of associations involved by the respondents. Only 14 respondents involved in the cultural, art, music, and, sport clubs, representing merely one percent of the whole sample. Though this was a small portion, I decided not to exclude the observations from the analysis so as to avoid a potential selection bias or the interaction among different type of associations. A binary CLUB variable then was constructed as a proxy of an individual's social capital value. CLUB $=1$ if respondent was a member to at least one association, and 0 otherwise.

Table 1. Numbers of respondents participated in social associations

\begin{tabular}{ll}
\hline Type of associations & Number of observations \\
\hline Religious organizations & 27 \\
Professional associations & 52 \\
Cultural, art, music, and, sport clubs & 14 \\
Educational related organizations & 7 \\
Voluntary associations & 53 \\
Political and non-profit organizations & 2 \\
0ther social associations & 113 \\
Total club members & $\mathbf{2 6 8}$ \\
\hline
\end{tabular}

Table 2 provides definitions and descriptive statistics of all variables. Of the 1,461 observations used in this study, the number of female observations was two folds that of male. About 50 percent of the sample considered themselves of having good or very good physical health, while about two-third (76 percent) reported that they had good or very good mental health.

In addition, the average elderly had only primary education which was a seven-year program before 1980. Our sample is in line with the 2010 Labour Force Survey indicating that more than half of Thailand labor force had primary or less education. 64 percent of the samples were married with an average of 2.66 children and 2.56 grandchildren supporting the forecast of a declining in population. Furthermore, parents' education also influences that of their children, for only 0.65 children of Thai elderly had a university degree. The average elderly lived in a household of 3 persons. 71 percent of the whole sample met their children at least once a month. Income distribution among the sample concentrated more on the middle to upper income class with only a quarter of the sample lied below the first income quartile. Finally, 46 percent of the sample lived in urban area with about 30 percent lived in Bangkok capital city.

Table 2. Descriptive statistics

\begin{tabular}{|c|c|c|}
\hline Variable name & Definition & Mean \\
\hline \multicolumn{3}{|l|}{ Dependent Var. } \\
\hline$\overline{\mathrm{SRH}_{p h y s i c a l}}$ & $\begin{array}{l}\text { Dummy variable equals to } 1 \text { if respondent reports of having good or very good } \\
\text { physical health, } 0 \text { otherwise. }\end{array}$ & 0.50 \\
\hline $\mathrm{SRH}_{\text {mental }}$ & $\begin{array}{l}\text { Dummy variable equals to } 1 \text { if respondent reports of having good or very good } \\
\text { mental health, } 0 \text { otherwise. }\end{array}$ & 0.76 \\
\hline CLUB & $\begin{array}{l}\text { Dummy variable equals to } 1 \text { if respondent reports of being a member of at least } \\
\text { one association, } 0 \text { otherwise. }\end{array}$ & 0.18 \\
\hline Soc_Multiplier & $\begin{array}{l}\text { Dummy variable equals to } 1 \text { if respondent participates in any associational } \\
\text { activities for at least once a month, } 0 \text { otherwise. }\end{array}$ & 0.13 \\
\hline Male & Dummy variable equals to 1 if respondent is male, 0 otherwise. & 0.33 \\
\hline Age & Respondent's age. & 60.08 \\
\hline Married & Dummy variable equals to 1 if respondent is married, 0 otherwise. & 0.64 \\
\hline Yrs_school & Number of years schooling of the respondent. & 7.24 \\
\hline Spouse_yrs_school & Number of years schooling of the respondent's spouse. & 6.23 \\
\hline HH_members & Number of people living in the same household as the respondent. & 3.11 \\
\hline Children & Number of children of the respondent. & 2.66 \\
\hline Children_month & $\begin{array}{l}\text { Dummy variable equals to } 1 \text { if respondent meet at least one of his children for at } \\
\text { least once a month, } 0 \text { otherwise. }\end{array}$ & 0.71 \\
\hline Children_year & $\begin{array}{l}\text { Dummy variable equals to } 1 \text { if 'Often-meet-child' }=0 \text {, and the respondent meets at } \\
\text { least one of his children few times a year, } 0 \text { otherwise. }\end{array}$ & 0.10 \\
\hline Children_not_see & $\begin{array}{l}\text { Dummy variable equals to } 1 \text { if respondent did not contact any of his children in the } \\
\text { past } 12 \text { months, } 0 \text { otherwise. (reference group) }\end{array}$ & 0.19 \\
\hline
\end{tabular}




\begin{tabular}{|c|c|c|}
\hline $\begin{array}{l}\text { Children } \\
\text { higher educ }\end{array}$ & Number of children with bachelor degree or higher. & 0.65 \\
\hline Grandchildren & Number of grandchildren of the respondent. & 2.56 \\
\hline Hrswork & Hours work per week. & 17.08 \\
\hline Recreation & $\%$ of time a week spent in recreation & 31.70 \\
\hline Low_income & $\begin{array}{l}\text { Dummy variable equals to } 1 \text { if respondent's personal income is less than the } 25^{\text {th }} \\
\text { income percentile of the whole sample, } 0 \text { otherwise. }\end{array}$ & 0.25 \\
\hline Middle_Income & $\begin{array}{l}\text { Dummy variable equals to } 1 \text { if respondent's personal income is greater than or } \\
\text { equal to the } 25^{\text {th }} \text { income percentile but less than the } 50^{\text {th }} \text { income percentile of the } \\
\text { whole sample, } 0 \text { otherwise. }\end{array}$ & 0.35 \\
\hline High_income & $\begin{array}{l}\text { Dummy variable equals to } 1 \text { if respondent's personal income is greater than or } \\
\text { equal to the } 50^{\text {th }} \text { income percentile of the whole sample, } 0 \text { otherwise. (reference }\end{array}$ & 0.40 \\
\hline $\operatorname{Ln}($ wealth$)$ & group) & \\
\hline $\operatorname{Ln}($ asset $)$ & Total non-labor income of the respondent (in log form). & 0.58 \\
\hline Ln(children & Total value of the respondent's asset (in log form). & 12.89 \\
\hline money) & Total cash transfer from all children in the past 12 months (in log from). & 5.82 \\
\hline In-kind income & $\begin{array}{l}\text { Dummy variable equals to } 1 \text { if respondent received any in kind transfer from his } \\
\text { children, } 0 \text { otherwise. }\end{array}$ & 0.29 \\
\hline Relative_educ & Relative yrs in school of the respondent compared to those in the same sub-district & 1.00 \\
\hline Retired & Dummy variable equals to 1 if respondent is retired, 0 otherwise. & 0.30 \\
\hline Employee & Dummy variable equals to 1 if respondent works as employee, 0 otherwise. & 0.11 \\
\hline Self-employed & Dummy variable equals to 1 if respondent is self-employed, 0 otherwise. & 0.34 \\
\hline Unpaid-family & Dummy variable equals to 1 if respondent is unpaid-family worker, 0 otherwise. & 0.01 \\
\hline Unemployed & $\begin{array}{l}\text { Dummy variable equals to } 1 \text { if respondent is unemployed, } 0 \text { otherwise. (reference } \\
\text { group) }\end{array}$ & 0.53 \\
\hline Childcare & $\begin{array}{l}\text { Dummy variable equals to } 1 \text { if respondent has to take care of at least one } \\
\text { grandchildren, } 0 \text { otherwise }\end{array}$ & 0.17 \\
\hline Cigarette & $\begin{array}{l}\text { Dummy variable equals to } 1 \text { if respondent smokes cigarette on regular basis, } 0 \\
\text { otherwise. }\end{array}$ & 0.10 \\
\hline Drink & $\begin{array}{l}\text { Dummy variable equals to } 1 \text { if respondent drink any alcohol on a regular basis, } 0 \\
\text { otherwise. }\end{array}$ & 0.14 \\
\hline Bangkok & Dummy variable equals to 1 if respondent resides in Bangkok, 0 otherwise & 0.30 \\
\hline Khonkaen & Dummy variable equals to 1 if respondent resides in Khon-kaen, 0 otherwise. & 0.42 \\
\hline Surrounding & $\begin{array}{l}\text { Dummy variable equals to } 1 \text { if respondent resides in surrounding provinces near } \\
\text { Bangkok, } 0 \text { otherwise (reference group) }\end{array}$ & 0.28 \\
\hline Urban & Dummy variable equals to 1 if respondent resides in urban area, 0 otherwise & 0.46 \\
\hline Friend & $\begin{array}{l}\text { Dummy variable equals to } 1 \text { if respondent meets closed friend at least once a } \\
\text { month, } 0 \text { otherwise }\end{array}$ & 0.82 \\
\hline
\end{tabular}

\section{Empirical Framework}

According to Glaeser, Laison, \& Sacerdote's (2002) model that explained an individual social capital accumulation over lifetime, the authors predicted that an individual's stock of social capital has a concave relationship with his age. An individual level of social capital declined after a certain age when his spouse, friends, or relatives move or pass away. Involvement in social groups can help to replenish the social networks that the elderly may loss overtime. In addition, Adam, Bay, Bonsang, Germain, \& Perelman (2006) found a correlation of a declining of an individual's cognitive skill with retirement. Sirven \& Debrand (2008) argued that social participation may help to slow down this process. For social activities will keep older adults active; some activities may require the exercise of either cognitive or non-cognitive skills, or both. Social participations thus improve both physical and mental health of the elderly.

While we want to prove whether involvement in voluntary activities contributes to good health, the reverse situation that healthy people are more active in voluntary associations is also plausibly. A simple regression of an individual $i$ 's Self-Reported Health $\left(S R H^{i}\right)$ on his $C L U B^{i}$ could produce an inefficient and inconsistent result. To address this potential causality that we observe only healthy elderly joining clubs, I employed the Bivariate Probit procedure to deal with the endogeneity problem by running the Probit regression of SRH in one equation with the $C L U B$ determinants in another equation simultaneously.

$$
\mathrm{SRH}_{j}^{i}=\beta_{0}+\beta_{1} X^{i}+\beta_{2} \text { living }^{i}+\beta_{3} \text { wealth }^{i}+\delta^{i}
$$




$$
C L U B^{i}=\alpha_{0}+\alpha_{1} \widetilde{X}^{i}+\alpha_{2} S o C_{-} \text {multiplier }{ }^{i}+\alpha_{3} \text { childcare }^{i}+\omega^{i}
$$

Subscript $j$ refers to physical and mental health. Two pairs of Bivariate Probit are examined; self-reported physical health of the ith respondent, $S R H_{\text {physical }}^{i}$, and his $C L U B^{i}$ membership, as well as, self-reported mental health of the ith respondent, $S R H_{\text {mental }}^{i}$, and his $C L U B^{i}$ membership respectively. Note that $\delta^{i}$ and $\omega^{i}$ are the random disturbance terms in which their correlation coefficient (RHO) can be used to test whether the correction for the endogeneity problem is necessary. A statistical significant estimated RHO implies that the specification is an efficient method for analysis, therefore, the Bivariate Probit estimation is appropriate in correcting the causality between the respondent self-reported health, $S R H_{j}^{i}$, and his $C L U B^{i}$ membership, otherwise the Univariate Probit can be applied to estimate each equation separately.

Although other econometric technique such as an instrument variable can be used to handle the endogeneity problem, I followed Sirven \& Debrand (2008) in using the Bivariate Probit procedure so as to perform a counterfactual experiment to evaluate if a policy promoting social participation can improve the overall health status of Thai elderly.

Since $S R H_{j}^{i}$ and $C L U B^{i}$ are two probabilities of reporting good or very good health and being a club member. Two situations are of particular interest here. One is the probability of reporting good health given that the respondent is a member to at least one association, $\operatorname{Prob}\left(S R H_{j}^{i}=1 / C L U B^{i}=1\right)$; another is the probability of reporting good health given that the respondent is not a member to any club, $\operatorname{Prob}\left(S R H_{j}^{i}=1 / C L U B^{i}=0\right)$. These two conditional probabilities can be calculated using the estimated results of the above Bivariate Probit model. We then compare the cumulative probability distribution of reporting good health under the two scenarios using the Generalized Lorenz Curves (GLC) method. The convexity of the GLC curves reflects the degree of health inequality. If social participation does improve health, health inequality should decline as more elderly part take in social activities.

Equation (1) classifies the factors that explain an individual health status unto 3 categories. ' $X$ ' refers to an individual's personal characteristics: - gender, age, marital status, and years in school of the respondent, and that of his spouse. An individual's 'living' arrangements that may influence his health status are examined, for instance, frequency of time meeting one own children, hours works per week, and percentage of time spent in recreation a week. All these factors could have either positive or negative influence on the elderly health.

An individual's level of 'wealth' can be used to measure the income security of whether the respondent has enough financial support in an unexpected situation like illness. Sample was divided according to the labor market income into low, middle and high income classes so as to test how the level of income affects an individual physical and mental health. Other wealth indicators such as non-labor market income from all sources, value of total asset, in-kind and in-cash remittances from one owns children were investigated. We later on compare whether financial or social capitals would have more influence on older adults' health status.

In this study, we use the respondent $i{ }^{\prime} C L U B^{i}$ membership as a proxy of his social capital value. In addition to gender and age variables, the respondent's relative years in school as compared to others residing in the same sub-district was included as an explanatory variable. Since adults with a higher educational attainment, in general, would have more opportunities to involve in formal associations, thus is more likely to be a member of formal organization than their counterparts with lower educational level. However, those who participated in the labour force might be active in their professional association, while those who retired may involve in different associations like religious or other voluntary organizations. Equation (2) thus analyzes a binary variable of whether the respondent was retired. If not, whether he was working as an employee, self-employed, unpaid-family, or looking for a job (unemployed). Working status of the respondent can capture time availability of the respondent for social activities and the type of associations he chose to participate.

Many Thai elderly also provided childcare for their adult's children who work outside the house. But childcare can take up social time of the elderly thus become a setback for social participation. Variable 'childcare' was a dummy equal to 1 if the respondent took care one of his grandchildren at home, 0 otherwise.

Since two respondents with similar observable characteristics could make a different decision of whether or not to participate in a club. Glaeser et.at., 2002 explained that an individual's decision to participate in any voluntary association was driven by the density of his social networks. Unfortunate that we could observe only whether the respondent was a club member but not the density of his networks for it is a 'latent' variable. To correct for the selection bias that we could observe only the social participation for those with a certain level of network density, we employed the Heckman procedure for Probit models (Greene, 2000) to solve the problem.

Following Sirven \& Debrand (2008), we used an estimation of 'location_effect' variable to generate a proxy for 
an individual network density called 'Soc_multiplier' in equation (2). 'Soc_multiplier' is an instrumental variable computed from the estimated coefficients of equation (3) as follows.

$$
\text { Location_effect }{ }^{i}=\lambda_{0}+\lambda_{1} \text { Bangkok }^{i}+\lambda_{2} \text { KhonKaen }^{i}+\lambda_{3} \text { Urban }^{i}+\lambda_{4} \text { friend }^{i}+\pi^{i}
$$

Location_effect ${ }^{i}$ is a dummy variable equals 1 if $i h$ respondent participates in any associational activities for at least once a month, and zero elsewhere. The frequency of social participation was used to indicate the density of an individual networks. We assume that people in the metropolitan area like Bangkok or in a big city like Khon-Kaen as well as those residing in urban area are less influenced by friends and neighbors to join voluntary activities compared to those in rural area where people are more connected thus make it difficult to avoid social participations. Furthermore, equation (3) also includes "friend" as a dummy variable to indicate whether the respondent has an extrovert characteristic. "Friend" is a dummy variable equal to 1 if the elderly associates with his friends at least once a month, 0 otherwise.

Note that equation (3) was used to correct for the selection bias of only the $C L U B^{i}$ equation. A simultaneous estimation of all three equations would be inappropriate as it will not solve the 'selection bias' problem, but complicate the counterfactual experiment in which we want to evaluate the impact of policy that favors social participation on the elderly health.

Before discussing the empirical results in the next section, notice that for the Bivariate Probit to be a correct method in dealing with the causality problem between $S R H_{j}^{i}$ and $C L U B^{i}$. It is important that the explanatory variables in the $C L U B^{i}$ equation should not be identical to those of $S R H_{j}^{i}$ equation. Or else, the Bivariate Probit could not be an appropriate procedure in correcting the casual effect. It is, therefore, worth to mention here that the relative education of the respondent as compared to others residing in the same sub-district, his work status, a childcare routine, and the Soc_multiplier instrumental variable are the explanatory variables only in the $C L U B^{i}$ equation and should not have any influence on the respondent's self-reported health $\left(S R H_{j}^{i}\right)$. For an individual to decide whether or not he had a good health, it is unlikely that the respondent will concern about the education of his neighbors, his working status (of whether he was an employee, self-employed, or unpaid family worker), his childcare work at home, or the level of social capital that he possessed. Our seeming unrelated Probit model thus was specified correctly.

\section{Empirical Results}

\subsection{Bivariate Probit Estimations}

Since equation (3) is a Univariate Probit specification; we used the marginal effects of the explanatory variable to determine how a small change in the independent variable can influence an individual probability to involve in social activities. Results in table 3 are in agreement with Sirven \& Debrand (2008). Whereas residing in Bangkok significantly reduces an individual probability of participating in social associations by approximately 0.12 compared to those living in the surrounding cities of Bangkok. Living in Khon-kaen, on the contrary, increases an individual probability of participating in social associations by 0.05 more than those in the surrounding cities of Bangkok. Meeting with friends for at least once a month also makes the elderly to become more active in social activities with an additional probability of 0.06 higher than those less mingle with others. The estimated coefficients of the Location_effect equation then are used to generate the 'Soc_multiplier' instrument for equation (2) as mentioned earlier.

Table 3. Marginal effects of the location_effect equation

\begin{tabular}{lll}
\hline Variables & Marginal effects $(\mathbf{d y} / \mathbf{d x})$ & z-stat \\
\hline Bangkok & $-0.123^{* * *}$ & -6.01 \\
Khon-kaen & $0.050^{* *}$ & 2.51 \\
Urban & 0.012 & 0.58 \\
Friend & $0.060^{* * *}$ & 3.30 \\
\hline
\end{tabular}

Note: $* * * 1 \%$ level of significance; $* * 5 \%$ level of significance.

Tables 4 reports the marginal effects for the probability of reporting good or very good physical health given that the respondent was a club member, $\operatorname{Prob}\left(S R H_{\text {physical }}^{i}=1 / C L U B^{i}=1\right)$. Similarly, $\operatorname{Prob}\left(S R H_{\text {mental }}^{i}=1 / C L U B^{i}=1\right)$ is the probability of reporting good or very good mental health given that the respondent was a club member.

First of all, it worth to mention that the Chi-square values of the log-likelihood Ratio (LR) test of the Bivariate Probit models between $S R H_{\text {physical }}^{i}$ and $C L U B^{i}$, and, between $S R H_{\text {mental }}^{i}$ and $C L U B^{i}$ differ significantly from zero with p-value less than 0.0001 for both specifications. The estimated RHOs (the correlation between the two disturbances; $\delta^{\mathrm{i}}$ and $\omega^{\mathrm{i}}$ ) are positively significant (with $\mathrm{p}=0.023$ for $S R H_{\text {physical }}^{i}$ and $C L U B^{i}$, and $\mathrm{p}=0.003$ for 
$S R H_{\text {mental }}^{i}$ and $C L U B^{i}$.) indicating that the seemingly unrelated Probit is an efficient method and the correction for selection bias is appropriate.

From table 4, notice that age, being married, and number of years in school are significant personal characteristics in explaining an individual's physical and mental health. While both physical and mental health deteriorates as the average respondent becomes older, education seems to help the elderly to take proper care of themselves. One-year increase in education significantly raises the probability of reporting good physical health of the average respondent by 0.023 and the probability of reporting good mental health by 0.008 suggesting a positive externality of education on health. Being married also improves health status according to the regression results; a married respondent, on average, has a higher probability of reporting good physical health by 0.085 and of good mental health by 0.048 compared to their non-married counterparts.

For financial capital variables, table 4 indicates that one percent increase in the non-labor market incomes, $\ln$ (wealth) variable, like income from rent, interest income, dividends, etc. increases an individual probability of reporting good physical health by 0.013 at 5 percent level of significance, while the value of asset is more important for the mental health. For one percent increase in the former significantly increases the latter by 0.006 .

For financial capital variables, table 4 indicates that one percent increase in the non-labor market incomes, $\ln$ (wealth) variable, like income from rent, interest income, dividends, etc. increases an individual probability of reporting good physical health by 0.013 at 5 percent level of significance, while the value of asset is more important for the mental health. For one percent increase in the former significantly increases the latter by 0.006 .

In addition, our results also show that the percentage of time a week spent in recreation, number of grandchildren, seeing one own child for at least once a year, and the higher education of children all contribute positively significantly to the mental health status of Thai elderly.

Table 4. Marginal effects of physical and mental health given that $i$ was a club member

\begin{tabular}{|c|c|c|c|c|}
\hline \multirow{2}{*}{ Variable Name } & \multicolumn{2}{|c|}{$\operatorname{Prob}\left(\right.$ for $\left.S R H_{\text {physical }}^{i}=1 / C L U B^{i}=1\right)$} & \multicolumn{2}{|c|}{$\operatorname{Prob}\left(S R H_{\text {mental }}^{i}=1 / C L U B^{i}=1\right)$} \\
\hline & Marg. Effect & z-stat & Marg. effect & z-stat \\
\hline \multicolumn{5}{|l|}{ 1.1Personal characteristics } \\
\hline Male & 0.048 & 1.53 & 0.021 & 1.05 \\
\hline Age & $-0.008 * * *$ & -4.49 & $-0.003 * * *$ & -2.89 \\
\hline Married & $0.085^{* *}$ & 2.48 & $0.048 * *$ & 2.01 \\
\hline Yrs_school & $0.023 * * *$ & 4.12 & $0.008^{* *}$ & 2.08 \\
\hline Spouse_yrs_school & -0.005 & -1.23 & 0.000 & -0.01 \\
\hline \multicolumn{5}{|l|}{1.2 Living arrangement } \\
\hline HH_members & -0.008 & -0.93 & $-0.011 *$ & -1.89 \\
\hline Children & -0.013 & -0.90 & -0.010 & -1.11 \\
\hline Children_month & 0.038 & 0.99 & 0.033 & 1.26 \\
\hline Children_year & 0.073 & 1.34 & $0.057^{*}$ & 1.84 \\
\hline Children_higher_educ & 0.017 & 1.07 & $0.019^{*}$ & 1.80 \\
\hline Grandchildren & 0.003 & 0.49 & $0.010^{* *}$ & 2.27 \\
\hline Hrswork & 0.013 & -0.74 & 0.000 & 1.25 \\
\hline Recreation & 0.003 & 1.14 & $0.001^{* *}$ & 2.03 \\
\hline \multicolumn{5}{|l|}{1.3 Individual wealth } \\
\hline Low_income & -0.020 & -0.52 & 0.000 & 0.02 \\
\hline Midd̄le_Income & -0.051 & -1.47 & $-0.049 *$ & -1.95 \\
\hline $\operatorname{Ln}($ wealth $)$ & $0.013^{* *}$ & 2.13 & 0.003 & 0.63 \\
\hline $\operatorname{Ln}($ asset) & 0.003 & 0.64 & $0.006^{* *}$ & 2.31 \\
\hline Ln(children money) & -0.003 & -1.10 & 0.001 & 0.69 \\
\hline In-kind income & -0.001 & -0.04 & 0.006 & 0.76 \\
\hline RHO & $0.128^{* *}$ & 2.28 & $0.191 * * *$ & 2.98 \\
\hline Log-likelihood Ratio & $-1412.7253^{* * *}$ & $217.05^{+++}$ & $-1238.7118^{* * *}$ & $179.88^{+++}$ \\
\hline
\end{tabular}

Note: $* * * 1 \%$ level of significance; ${ }^{* *} 5 \%$ level of significance; $* 10 \%$ level of significance, and, ${ }^{+++}$Chi-square statistics. 


\subsection{Counterfactual Experiment}

The estimated results of the above seemingly unrelated Probit model can be used to predict an individual's probability of reporting good or very good health in four scenarios; $\operatorname{Prob}\left(S R H_{\text {physical }}^{i}=1 / C L U B^{i}=1\right)$; $\operatorname{Prob}\left(S R H_{\text {physical }}^{i}=1 / C L U B^{i}=0\right) ; \operatorname{Prob}\left(S R H_{\text {mental }}^{i}=1 / C L U B^{i}=1\right) ; \operatorname{Prob}\left(S R H_{\text {mental }}^{i}=1 / C L U B^{i}=0\right)$.

We first compared the predicted probability under each scenario with the actual $S R H^{i}$ from the survey. Recall that 18 percent of the respondents were members to at least one association. Table 5 reports the means test and the two-sample Kolmogorov-Smirnov test of whether the probability distribution of reporting good or very good heath for those involving in social activities $\left(c l u b^{i}=1\right)$ differs significantly from those who do not participate in any social activities $\left(c l u b^{i}=0\right)$. The results obviously indicate that the predicted probability of the former is higher by 0.065 for physical health and 0.0838 for the mental health at 1 percent level of significance.

Recall from the Bivariate Probit results that one percent increase in the non-labour market income or Ln(wealth) of the respondent, on average, significantly increases his probability of reporting good physical health by 0.013 , whereas a percent increase in the respondent's value of asset increases his probability of reporting good mental health by 0.006 at 5 percent level of significance (see Table 4). Therefore, the contribution of social participations to good physical health is equivalent to a 5 percent $(0.065 / 0.013)$ increase in the individual non-labor market income, while the contribution of social participations to good mental health is equal to an approximation of 14 percent $(0.0838 / 0.006)$ increase in the asset value of older adults.

The probabilities of reporting good health of the average respondent also increase by 0.0536 for physical health and by 0.0706 for mental health if we can force all respondents to join at least one voluntary associations $(\mathrm{club}=1)$. The results hence suggest the importance of social participations to the mental health rather than the physical health of the elderly.

Table 5. Mean-test and the probability distributional test of good health

\begin{tabular}{lllll}
\hline Differences & Mean-test & p-value & K-S Dist. & p-value \\
\hline 1. $S R H_{\text {physical }}-\operatorname{Prob}\left(S R H_{\text {physical }}=1 / C L U B^{i}=1\right)$ & $-0.0536^{* * *}$ & 0.000 & $0.0963^{* * *}$ & 0.000 \\
2. $S R H_{\text {physical }}-\operatorname{Prob}\left(S R H_{\text {physical }}=1 / C L U B^{i}=0\right)$ & 0.0115 & 0.229 & 0.0283 & 0.672 \\
3. $\operatorname{Prob}\left(S R H_{\text {physical }}=1 / C L U B^{i}=1\right)-\operatorname{Prob}\left(S R H_{\text {physical }}=1 /\right.$ & $0.0650^{* * *}$ & 0.000 & $0.1147^{* * *}$ & 0.000 \\
$\left.C L U B^{i}=0\right)$ & $-0.0706^{* * *}$ & 0.000 & $0.2108^{* * *}$ & 0.000 \\
4. $S R H_{\text {mental }}-\operatorname{Prob}\left(S R H_{\text {mental }}=1 / C L U B^{i}=1\right)$ & $0.0132^{* *}$ & 0.020 & $0.0610^{* *}$ & 0.016 \\
5. $S R H_{\text {mental }}-\operatorname{Prob}\left(S R H_{\text {mental }}=1 / C L U B^{i}=0\right)$ & & & & \\
6. $\operatorname{Prob}\left(S R H_{\text {mental }}=1 / C L U B^{i}=1\right)-\operatorname{Prob}\left(S R H_{\text {mental }}=1 / C L U B^{i}\right.$ & $0.0838^{* * *}$ & 0.000 & $0.2595^{* * *}$ & 0.000 \\
$=0)$ & & & & \\
\hline
\end{tabular}

Note: $* * * 1 \%$ level of significance; $* * 5 \%$ level of significance; $* 10 \%$ level of significance.

Finally, figures 1 and 2 compare the cumulative distribution of the actual $S R H_{j}^{i}$ with the predicted probabilities given $c l u b^{i}=1$ and $c l u b^{i}=0$ respectively. The Generalized Lorenz Curves (GLCs) show how involvement in voluntary associations helps to improve the health inequality among Thai elderly.

In both figures, the green lines represent the cumulative probability of reporting good or very good health given that all respondents take part in social associations, $\operatorname{Prob}\left(S R H_{j}^{i}=1 / C L U B^{i}=1\right)$; the red lines are the cumulative distribution of actual $S R H_{j}^{i}$, and, the blue lines refer to the cumulative probability of reporting good health assuming that all respondents do not participate in any social associations, $\operatorname{Prob}\left(S R H_{j}^{i}=1 / C L U B^{i}=0\right)$ respectively. From both diagrams, observe that participating in social clubs makes the probability of reporting good health to distribute more evenly among the elderly for both their physical and mental health. Participating in social associations, therefore, reduces health inequality among Thai elderly, while the absent of such activities widen the gap. 


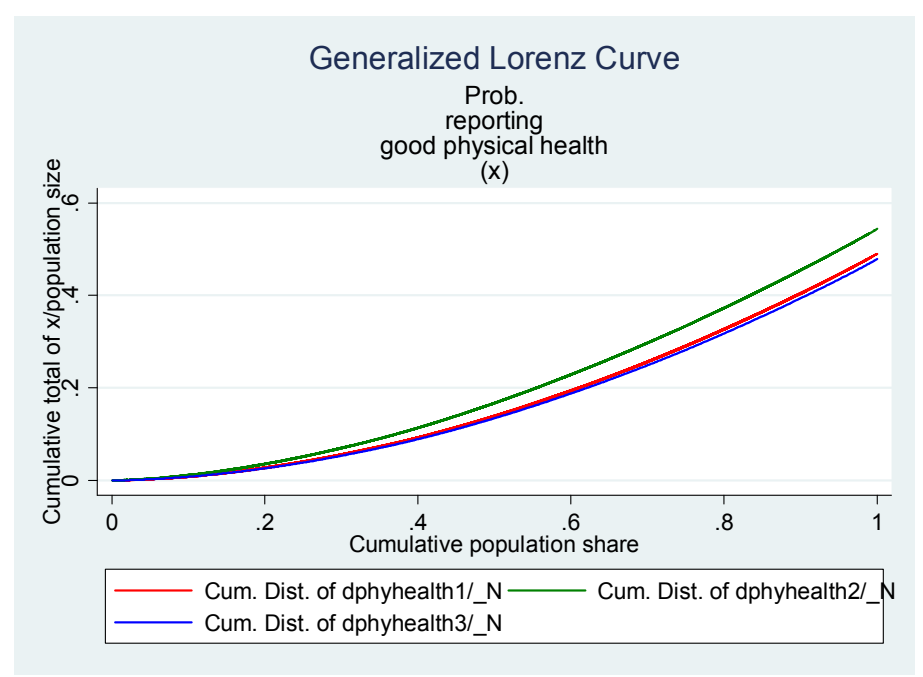

Figure 1. The impact of social participation on the elderly physical health

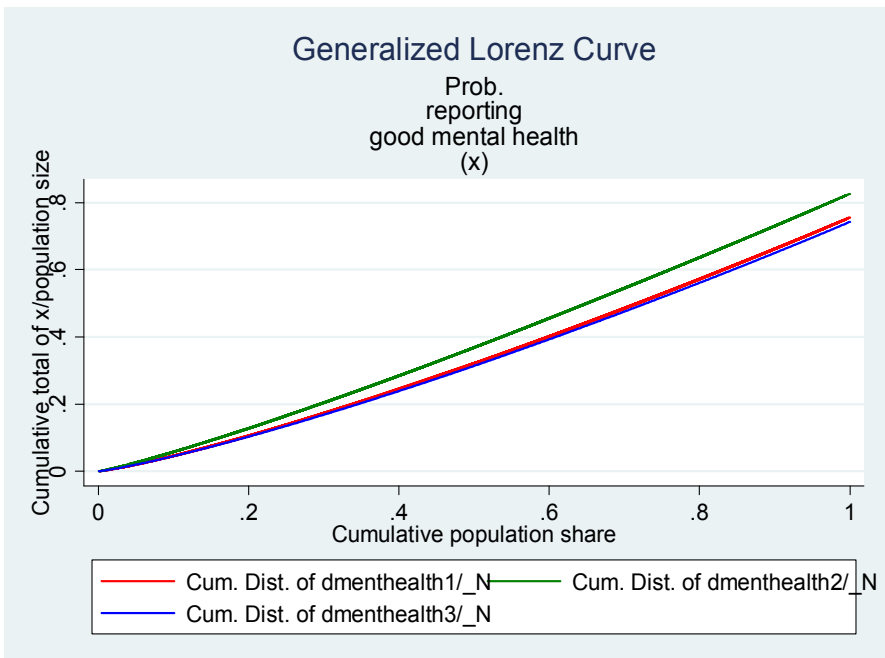

Figure 2. The impact of social participation on the elderly mental health

\section{Concluding Remarks}

For the number of ageing population in Thailand has been increased rapidly. The country was ranked as the most aged economy in South-east Asia after Singapore. However, there exists a body of research that associates social connectedness with good health. It is, therefore, the objective of this study to examine of whether the correlation holds for Thailand.

Using the first round pilot survey on Health, Ageing and Retirement in Thailand (HART), the study found that being married and, the level of education of the respondent contribute positively significantly to the probability of reporting good physical and mental health. The more the elderly participate in social activities, the higher the probability of reporting good or very good health, in particular, the mental health. Social participations to good physical health is an income equivalence of a 5 percent increase in an individual non-labor income, whilst social participations to good mental health accounts to almost 14 percent increase in the total asset value. Participating in voluntary associations thus reduces heath inequalities among older people. The research findings hence advocate for the social involvement of elderly people as a part of the quality ageing policy and the community-based welfare policy.

\section{References}

Adam, S., Bay, C., Bonsang, E., Germain, S., \& Perelman, S. (2006, May). Occupational activities and cognitive reserve: a frontier approach applied to the survey of health, ageing, and retirement in Europe (SHARE). CREPP WP. HEC School of Management, Belgium: University of Liege (Mimeo). 
Glaeser, E. L., Laibson, D., \& Sacerdote, B. (2002). The economic approach to social capital. Economic Journal, 112, 437-458. http://dx.doi.org/10.1111/1468-0297.00078

Ichida et al. (2009). Social capital, income inequality and self-rated health in Chita peninsula, Japan: a multilevel analysis of older people in 25 communities. Social Science and Medicine, 69, 489-499. http://dx.doi.org/10.1016/j.socscimed.2009.05.006

Islam, M. K., Merlo, J., Kawachi, I., Lingstrom, M., \& Gerthan, U. (2006). Social capital and health: does egalitarianism matter? A literature survey. International Journal for Equity in Health, 5, 1-28. http://dx.doi.org/10.1186/1475-9276-5-3

Putnam, R. D. (2000). Bowing alone: The Collapse and revival of American community. New York: Simon and Schuster.

Sirven, N., \& Debrand, T. (2008). Social participation and healthy ageing: An international comparison using SHARE data. Social Science and Medicine, 67, 2017-2026. http://dx.doi.org/10.1016/j.socscimed.2008.09.056

Szreter, S., \& Woolcock, M. (2004). Health by association? Social capital, social theory, and the political economy of public health. International Journal of Epidemiology, 33, 650-667. http://dx.doi.org/10.1093/ije/dyh013

UNFPA. (2006). Population Ageing in Thailand: Prognosis and Policy Response. United Nations Population Fund, Thailand. Retrieved from http://thailand.unfpa.org/documents/thai_ageing_englishversion.pdf 